\title{
Effects of phenolics from Oplismenus undulatifolius in $\alpha$-MSH-stimulated B16F10 melanoma cells
}

\author{
Hye-Jin Park ${ }^{1} \cdot$ Eun-Ho Lee ${ }^{1} \cdot$ Hee-Young Jung ${ }^{2} \cdot$ In-Kyu Kang ${ }^{3} \cdot$ Young-Je Cho $^{1}$
}

Received: 3 February 2020 / Accepted: 6 March 2020 / Published Online: 31 March 2020

(C) The Korean Society for Applied Biological Chemistry 2020

\begin{abstract}
In this study, the efficacy of melanoma cell B16F10 was investigated using the Korean native plant Oplismenus undulatifolius (OU). First, the cell viability of the extract was more than $90 \%$ when treated with $15 \mu \mathrm{g} / \mathrm{mL}$ of phenolics from OU. The results showed that melanin biosynthesis and cellular tyrosinase synthesis were inhibited by treatment with $\alpha$ melanocyte-stimulating hormone-stimulated mouse melanoma cell B16F10 at a concentration of $15 \mu \mathrm{g} / \mathrm{mL}$ of phenolics for cellline efficacy. The expression of tyrosinase, tyrosinase-related protein (TRP)-1, TRP-2, and microphthalmia transcription factor (MITF) protein was confirmed by western blot to investigate the effect of phenolics from OU on melanin biosynthesis. When treated with phenolics from OU $15 \mu \mathrm{g} / \mathrm{mL}$, tyrosinase, TRP-1, TRP-2, and MITF decreased the protein expression level. In particular, tyrosinase, TRP-1, and MITF inhibited the production amount to a level similar to that of the non-treated normal group, indicating that the effect was excellent. Therefore, phenolics from OU acts as an inhibitor of tyrosinase, TRP-1, TRP-2, and its transcription factor MITF, and participates in melanin biosynthesis mechanism. These results suggested the potential for development as a material.
\end{abstract}

Keywords B16F10 mouse melanoma cells, Extract · $\alpha$-Melanocytestimulating hormone-stimulation · Oplismenus undulatifolius

Young-Je Cho $(\bowtie)$

E-mail:yjcho@knu.ac.kr

${ }^{1}$ School of Food science \& Biotechnology, Kyungpook National University, 80 University Street, Bukgu, Daegu 41566, Republic of Korea

${ }^{2}$ School of Applied Biosciences, Kyungpook National University, 80 University Street, Bukgu, Daegu 41566, Republic of Korea

${ }^{3}$ Department of Horticultural Science, Kyungpook National University, 80 Daehakro, Bukgu, Daegu 41566, Republic of Korea

This is an Open Access article distributed under the terms of the Creative Commons Attribution Non-Commercial License (http://creativecommons. org/licenses/by-nc/3.0/) which permits unrestricted non-commercial use, distribution, and reproduction in any medium, provided the original work is properly cited.

\section{Introduction}

In 1992, according to the United Nations Convention on Biological Diversity, the exclusive right of each country's plant resources was recognized. As a result, competition for industrialization is intensifying, for example, by searching for and obtaining plant genetic resources among countries [1]. In accordance with such international changes and trends, the importance of national support and active development and utilization of forest resource plants is emphasized.

Among the vast array of physiologically active compounds present in plants, plant-produced anti-oxidative polyphenolic compounds are known to protect the plants from various hazardous conditions, such as cell-damaging ultraviolet irradiation, cellular oxidative stress, and pest attacks. Notably, some of these polyphenolic compounds (e.g., flavonoids and acidic phenolic compounds) are known to have diverse beneficial physiological activities in humans, including anti-oxidative, anti-allergic, antidiabetic, anticancer, anti-inflammatory, skin whitening, and antiwrinkle effects $[2,3]$. Owing to its antioxidant potential with low toxicity, several articles have assessed its use as an active extract of cosmetic ingredients. Therefore, the development of healthrelated functional foods and food ingredients has considerable scope in terms of efficient utilization of natural resources, the development of new food resources, and the development of new materials.

Oplismenus undulatifolius (OU) is a perennial herbaceous plant of Gramineae that is commonly found in the forests and is widely distributed in the Far East, mainly in Central Asia in the Korean and Mediterranean coasts, northern India [4]. OU is currently used as livestock feed, but it is rarely known as a medicinal resource, and all of the natural substances contained in this plant are isoarborinol, cylindrin, and triedelin, all of which are triterpenoid components [5].

Recently, many types of researches and developments have been made in the field of functional foods and functional cosmetics for superior functional materials derived from medicinal plant 
resources that have been proven to be effective [6,7]. Also, significant research is underway in terms of the efficient use of natural resources and contribution to the development of new materials [8].

Melanin is a pigment that forms between the lower layer of the epidermis and the dermis. It is a beneficial substance that is produced to protect cells against external stimuli such as ultraviolet rays [9]. However, excessive or abnormal melanin production in the body may cause skin pigmentation, freckles, and skin irritation as well as skin cancer [10]. Tyrosinase is the most important enzyme in the production of melanin in the skin. It converts tyrosine in the melanosome of melanocyte into DOPA and DOPA quinone during melanin biosynthesis. DOPA chrome is metabolized by indole-5,6-quinone carboxylic acid and indole-5,6-quinone by enzymatic action and autoxidation. Finally, melanin is synthesized [11]. In this process, the expression of cellular tyrosinase, microphthalmia transcription factor (MITF), tyrosinase-related protein (TRP)-1, and TRP-2 protein, which are involved in the production of melanin pigment by molecular biology, increases in cells. When excessive melanin is produced, the skin tone becomes dark and dark circles, spots and freckles appear on the surface of the skin.

B16F10 mouse melanoma cell inhibited cellular tyrosinase inhibitory activity and inhibited the expression of proteins involved in melanin production such as MITF, TRP-1, and TRP2. Based on the experimental results, the efficacy of the effect was confirmed.

\section{Materials and Methods}

\section{Preparation of phenolic samples}

Lee et al. [12] reported that the biological activities of OU for functional cosmetic ingredients or other physiological supplements were expressed by phenolics in OU. Thus, the preparation of phenolics from OU has carried out the following step.

$\mathrm{OU}$, which is a native herbaceous plant on the hillside, Korea, was sampled and dried at $50{ }^{\circ} \mathrm{C}$ in a dry oven and pulverized to 40 mesh. The sample was vacuum packed and stored at $4{ }^{\circ} \mathrm{C}$ for cold storage. Phenolic extraction from the sample was performed by adding $500 \mathrm{~mL}$ of $70 \%$ ethanol to $10 \mathrm{~g}$ of dried OU powder and stirring at room temperature for $24 \mathrm{~h}$ at $120 \mathrm{rpm}$. The phenolic solution was filtered through Whatman No. 1 filter paper. After removing all of the ethanol by using a rotary vacuum evaporator (Eyela NE, Tokyo, Japan), it was lyophilized and used as a sample.

\section{Cell culture}

In this study used mouse melanoma cell B16F10, was purchased from American type culture collection (ATCC; Manassas, VA, USA). Cell culture was performed with $10 \%$ fetal bovine serum (FBS, HyClone Laboratories, Inc, Logan, Utah, USA) and 1\% penicillin/streptomycin (100 U/mL, HyClone Laboratories, Inc.) in Dulbecco's Modified Eagle's Medium (DMEM, HyClone Laboratories, Inc.) was added and the cells were subcultured in a $5 \% \mathrm{CO}_{2}$ incubator at $37^{\circ} \mathrm{C}$ and seeded at the appropriate numbers into wells of the cell culture plate for further experiments.

\section{MTT assay}

To determine the quality of the various extracts the viability of cells following treatment with extracts was determined by the 3[4,5-dimethylthiazol-2-yl]-2,5-diphenyltetrazolium bromide (MTT) assay. B16F10 cells were seeded on 48 well plates at $5 \times 10^{3}$ cells/ well using the method of Carmichael et al. [13] for measuring the cell viability of the samples. And incubated in a $5 \% \mathrm{CO}_{2}$ incubator at $37^{\circ} \mathrm{C}$ for $24 \mathrm{~h}$ to stabilize. After the culture medium was removed, the phenolics were treated with concentrations of 1 , $5,10,15$, and $20 \mu \mathrm{g} / \mathrm{mL}$ and cultured for $24 \mathrm{~h}$. Then, $5 \mathrm{mg} / \mathrm{mL}$ MTT (Sigma-Aldrich Co., Louis, MO, USA) reagent was added and reacted for $4 \mathrm{~h}$. After completion of the incubation, all of the culture medium was removed, $500 \mu \mathrm{L}$ of dimethyl sulfoxide was added to each well, reacted at room temperature for $10 \mathrm{~min}$, and absorbance was measured at $540 \mathrm{~nm}$ using an enzyme-linked immunosorbent assay (ELISA) reader (SPECTRO star Nano, BMG LABTECH, Ortenberg, Germany). Cell viability was expressed as the absorbance reduction rate of the sample solution addition group and the no addition group.

\section{Cell stimulus and phenolics treatment}

To stimulate B16F10 cells, $100 \mathrm{nM} \alpha$-melanocyte stimulating hormone (MSH) was added to each dish except for the nontreated group after seeding to $5 \times 10^{5}$ cells/well in a $100 \mathrm{~nm}$ cell culture dish. After $1 \mathrm{~h}$, the phenolics were treated with concentrations $(1,5,10,15$, and $20 \mu \mathrm{g} / \mathrm{mL})$ and cultured for $24 \mathrm{~h}$.

\section{Inhibitory activity of cellular tyrosinase}

All of the culture broth was removed from B16F10 cells after stimulation and phenolics treatment. After washing twice with cold PBS, $250 \mu \mathrm{L}$ of lysis buffer per well was added to dissolve the cells. The lysis buffer was a mixture of mammalian protein extraction reagent (M-PER) (Thermo Fisher Scientific, Waltham, MA, USA) and protease inhibitor (Thermo Fisher Scientific). The mixture was centrifuged at $13,000 \mathrm{rpm}$ for $15 \mathrm{~min}$ at $4{ }^{\circ} \mathrm{C}$ to remove protein components. Then, $40 \mu \mathrm{L}$ of the supernatant was added to each well of a 96 well plate and mixed with $160 \mu \mathrm{L}$ of $10 \mathrm{mM}$ 3,4-Dihydroxy-L-phenylalanine (L-DOPA) substrate dissolved in $0.1 \mathrm{M}$ sodium phosphate buffer ( $\mathrm{pH} 6.8)$. After incubation at $37^{\circ} \mathrm{C}$ for $1 \mathrm{~h}$, the amount of DOPA chrome produced was measured at $490 \mathrm{~nm}$ with an ELISA reader (SPECTRO star Nano, BMG LABTECH) to confirm cellular tyrosinase inhibitory activity.

\section{Inhibitory activity of melanin production}

The culture medium was removed from the B16F10 cells that had 
been subjected to stimulation and phenolics treatment by the method of Hosoi et al. [14] and washed twice with cold PBS. Then, a mixture of M-PER and protease inhibitor was used as lysis buffer and $250 \mu \mathrm{L}$ was added to dissolve the cells, and the supernatant was removed by centrifugation at 13,000 rpm for 15 min at $4{ }^{\circ} \mathrm{C}$, and the pellets of the separated cells were collected and dried. To the isolated pellet, $200 \mu \mathrm{L}$ of $1 \mathrm{~N} \mathrm{NaOH}$ was added and reacted at $70{ }^{\circ} \mathrm{C}$ for $1 \mathrm{~h}$. Melanin content was measured at 405 $\mathrm{nm}$ using an ELISA reader (SPECTRO star Nano, BMG LABTECH) to confirm melanin biosynthesis inhibitory activity.

\section{Western blot analysis}

Western blot analysis was performed using Tsareva et al. [15]. After the culture medium was removed, stimulated and phenolicstreated B16F10 cells were washed twice with cold PBS, and the cells were lysed by adding $250 \mu \mathrm{L}$ of lysis buffer (M-PER and protease inhibitor mixture) per well. After centrifugation at 13,000 rpm for 15 min at $4{ }^{\circ} \mathrm{C}$, the supernatant was separated and proteins were quantitated using the BCA assay kit (Thermo Fisher Scientific). Then, $20 \mu \mathrm{L}$ of protein was separated by electrophoresis using $10 \%$ sodium dodecyl sulfate-polyacrylamide gel electrophoresis. The separated proteins were transferred to a PVDF membrane at $60 \mathrm{~V}$ for $2 \mathrm{~h}$ and $30 \mathrm{~min}$ to inhibit the nonspecific binding of the antibody. The resulting protein was transferred to $5 \%$ bovine serum albumin dissolved in $1 \times$ Tris-Buffered Saline Tween (TBST)-and the background was removed. After washing with $1 \times$ TBST every $10 \mathrm{~min}$ three times, the primary antibodies were diluted in proportions with tyrosinase (T311, 1:500, Thermo Fisher Scientific), MITF (N2C1, 1:500, GeneTex, Irvine, CA, USA), TRP-1 (G-9, 1:100, Santa Cruz Biotechnology, Dallas, TX, USA), TRP-2 (E-10, 1:100, Santa Cruz Biotechnology) and GAPDH (GA1R, 1:1,000, Thermo Fisher Scientific), respectively, and reacted overnight at $4{ }^{\circ} \mathrm{C}$. The membranes were washed three times with $1 \times$ TBST for $10 \mathrm{~min}$, the cells were incubated with goat anti-mouse IgG1-HRP (sc-2060, 1:500, Santa Cruz Biotechnology) for tyrosinase, TRP-1, TRP-2, and GAPDH as secondary antibodies were used. MITF was reacted with mouse anti-rabbit IgG-HRP (sc-2357, 1:500, Santa Cruz Biotechnology) at room temperature for $1 \mathrm{~h} 30 \mathrm{~min}$. After washing with $1 \times$ TBST for $10 \mathrm{~min}$ three times, it was reacted with Super Signal West Pico PLUS Chemiluminescent Substrate (Thermo Fisher Scientific) solution. And it was transferred to film. The band was developed using a C 300 image analyzer (Azure Biosystems, Dublin, CA, USA). And density was quantitated.

\section{Statistical analysis}

All tests were performed in triplicate $(n=3)$. Statistical analysis was conducted using one-way ANOVA in IBM SPSS Statistics 25 (Statistical Package for Social Science, Chicago, IL, USA). Duncan's multiple range tests were performed to analyze differences. A $p$-value of less than ${ }^{*} p<0.05,{ }^{* *} p<0.01$ was considered to indicate a significant difference.

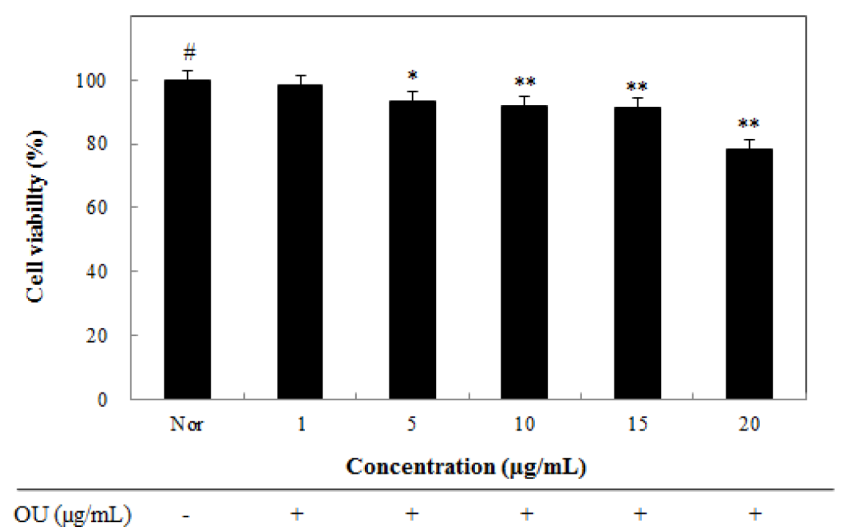

Fig. 1 Cell viability in B16F10 melanoma cells by phenolics from OU. $5 \times 10^{3}$ cells were seeded in serum-free medium for $24 \mathrm{~h}$, the cells were treated from normal or different concentration $(1,5,10,15$, and $20 \mu \mathrm{g}$ / $\mathrm{mL}$ ) of phenolics for $24 \mathrm{~h}$. Nor: not treated ethanol extracts. Data represent means \pm SD of three independent experiments $(n=3)$. The values are mean $\pm \mathrm{SD}$ of three independent experiments. ${ }^{*} p<0.05$ compared with the Nor group, $* p<0.05, * * p<0.01$ compared with the Nor group

\section{Results and Discussion}

\section{Cell viability}

The results of the MTT assay to evaluate the cytotoxicity of B16F10 melanoma cells of phenolics from OU were shown in Fig. 1. The cell viability of the untreated group was normalized to $100 \%$. Phenolics of OU were treated at concentrations of $1,5,10$, 15 , and $20 \mu \mathrm{g} / \mathrm{mL}$. At the concentrations of $1,5,10$, and $15 \mu \mathrm{g} /$ $\mathrm{mL}$, cell viability was about $90.0 \%$ or higher. However, the cell viability was $78.5 \%$ at the concentration of $20 \mu \mathrm{g} / \mathrm{mL}$. This means that it is toxic at a concentration of $20 \mu \mathrm{g} / \mathrm{mL}$. Based on the above results, the experiment was conducted at a maximum concentration of $15 \mu \mathrm{g} / \mathrm{mL}$ in the subsequent experiments. This is because the cell survival rate was more than $90.0 \%$ at the concentration of $15 \mu \mathrm{g} / \mathrm{mL}$.

\section{Inhibition of melanin production by phenolics from $\mathrm{OU}$ in B16F10 melanoma cells}

Melanin is a pigment component that forms between the lower layer of the epidermis and the dermis. If it is produced excessively on the skin due to external stimuli, skin pigmentation, freckles, skin inflammation, and skin cancer can occur $[9,10]$. The inhibitory effect of phenolics of $\mathrm{OU}$ on melanin biosynthesis against B16F10 melanoma cell stimulated with $\alpha-\mathrm{MSH}$ was confirmed in Fig. 2. Controls were only stimulated with $\alpha-\mathrm{MSH}$. The amount of melanin produced by the control was $100 \%$. And the treatment of phenolics from $\mathrm{OU}$ at 10 , and $15 \mu \mathrm{g} / \mathrm{mL}$ showed $87.7 \%$, and $81.8 \%$ production, respectively. And the amount of production was decreased in a concentration-dependent manner. 


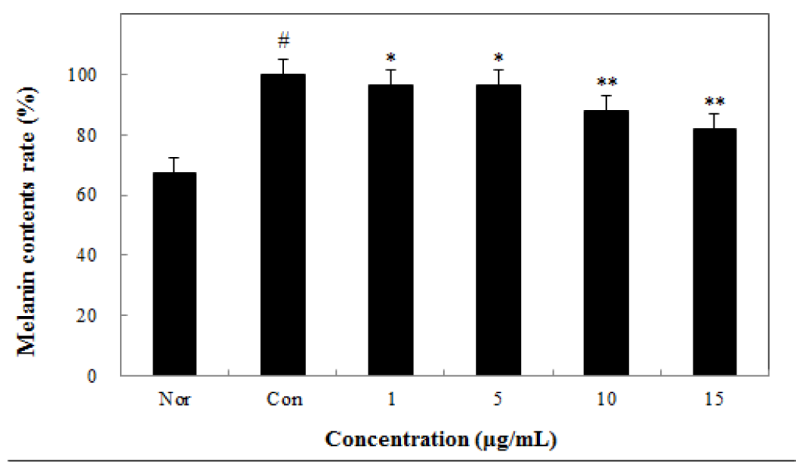

$\alpha-\mathrm{MSH}(100 \mathrm{nM})$

$\mathrm{OU}(\mu \mathrm{g} / \mathrm{mL})$

$+$

$+\quad+$

$+\quad+$

Fig. 2 Inhibitory effect of melanin contents by phenolics from $\mathrm{OU}$ treatment in B16F10 melanoma cells. $5 \times 10^{5}$ cells were seeded and stimulated to $\alpha$-MSH $100 \mathrm{nM}$ for $1 \mathrm{~h}$, the cells were treated from control or different concentration $(1,5,10$, and $15 \mu \mathrm{g} / \mathrm{mL})$ of phenolics for $24 \mathrm{~h}$. Nor: $\alpha$-MSH not induced group, Con: $\alpha$-MSH induced group not treated phenolics. The values are mean $\pm \mathrm{SD}$ of three independent experiments. ${ }^{\sharp} p<0.05$ compared with the Con group, ${ }^{*} p<0.05,{ }^{* *} p<0.01$ compared with the Con group

Inhibition of intracellular tyrosinase activity by phenolics from $\mathrm{OU}$ in B16F10 melanoma cells

In Fig. 3 shows the results of the measurement of cellular tyrosinase activity in B16F10 melanoma cells stimulated with $\alpha$ MSH to confirm tyrosinase inhibitory activity, a key enzyme involved in melanin biosynthesis. The activity level of cellular tyrosinase was $89.1,82.9$, and $73.3 \%$, respectively, when phenolics of OU was treated at 5,10 , and $15 \mu \mathrm{g} / \mathrm{mL}$, respectively. Especially at the concentration of $15 \mu \mathrm{g} / \mathrm{mL}$, cellular tyrosinase activity was similar to that of normal without stimulation. At this time, the amount of normal was $72.0 \%$. Therefore, it was confirmed that phenolics of OU markedly inhibited cellular tyrosinase enzyme activity. These results suggest that phenolics of OU inhibit the synthesis of intracellular tyrosinase in melanocyte and inhibit melanin biosynthesis. As a result, it was confirmed to have efficacy.

Conformation of inhibition of tyrosinase, MITF, TRP-1, and TRP-2 protein expression using western blot analysis with phenolics of $\mathrm{OU}$

Melanin in the skin is synthesized by enzymatic reactions such as tyrosinase, TRP-1, and TRP-2 [16]. MITF, a transcription factor involved in the expression of tyrosinase and TRP-1, is involved in melanin biosynthesis by promoting the expression of tyrosinase enzyme, which has the greatest effect on melanin biosynthesis [17]. In this study, the expression level of tyrosinase, TRP-1, TRP2, and MITF was confirmed to examine the effect of phenolics of OU on melanin biosynthesis. The results are shown in Fig. 4. When the amount of tyrosinase protein produced by the $\alpha$-MSHstimulated B16F10 melanoma cell was 100\%, the expression of tyrosinase protein decreased to $42.5 \%$ at the concentration of 15 $\mathrm{g} / \mathrm{mL}$ of phenolics from OU. This value was similar to that of

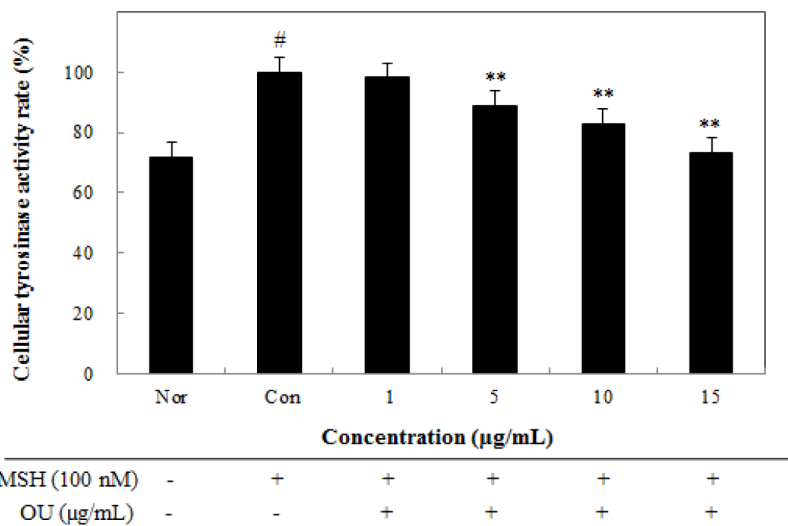

Fig. 3 Inhibitory effect of cellular tyrosinase activity by phenolics from OU treatment in B16F10 melanoma cells. $5 \times 10^{5}$ cells were seeded and stimulated to $\alpha$-MSH $100 \mathrm{nM}$ for $1 \mathrm{~h}$, the cells were treated from control or different concentration $(1,5,10$, and $15 \mu \mathrm{g} / \mathrm{mL})$ of phenolics for $24 \mathrm{~h}$. Nor: $\alpha$-MSH not induced group, Con: $\alpha$-MSH induced group not treated phenolics. The values are mean $\pm \mathrm{SD}$ of three independent experiments. ${ }^{\#} p<0.05$ compared with the Con group, ${ }^{*} p<0.05,{ }^{*} p<0.01$ compared with the Con group

normal without stimulation. The amount of normal was $55.3 \%$ (Fig. 4A). In the case of TRP-1, the expression level of $40.7 \%$ when treated with $15 \mu \mathrm{g} / \mathrm{mL}$ of phenolics from OU, compared with control. This is better than normal (Fig. 4B). In the case of TRP-2, the expression level of $66.5 \%$ when phenolics of OU was treated at a concentration of $15 \mu \mathrm{g} / \mathrm{mL}$ compared to control. This value inhibited $34.5 \%$ protein expression compared to control (Fig. 4C). In the case of MITF, the transcription factor, the expression level of MITF protein was $49.1 \%$ at the treatment with phenolics of $\mathrm{OU} 15 \mu \mathrm{g} / \mathrm{mL}$ compared with control. It was confirmed that this level is similar to that of $50.9 \%$ protein expressed by normal (Fig. 4D). These results indicate that phenolics of $\mathrm{OU}$ inhibits melanin pigment biosynthesis by significantly inhibiting tyrosinase, TRP-1, TRP-2, and protein expression of their transcription factor MITF. Therefore, it was expected that phenolics of OU could be developed as a functional material.

\section{References}

1. Korea forest seed and variety center (KFSV) (2009) Life characteristics of plant resources from Korea forest. Chungju

2. Lee EH, Kim MU, Kang IK, Park KI, Cho YJ (2018) Inhibitory activities of extracts from Hypericum ascyron L. on biological enzymes. J Korean Soc Food Sci Nutr 47: 7-14

3. Park SY, Song IH, Cho YJ (2018) Elicitor treatment potentiates the preventive effect of Saururus chinensis leaves on stress-induced gastritis. Appl Biol Chem 61: 423-431

4. Lee TB (1999) Illustrated flora of Korea. Hyangmunsa, Seoul

5. Ohmoto T, Ikuse M (1970) Triterpenoids of the gramineae. Phytochem 9: $2137-2148$

6. Rice-Evans CA, Miller NJ, Paganga G (1996) Structure-antioxidant activity relationships of flavonoids and phenolic acids. Frdd Rad Biol Med 20: 933-956 
(A)
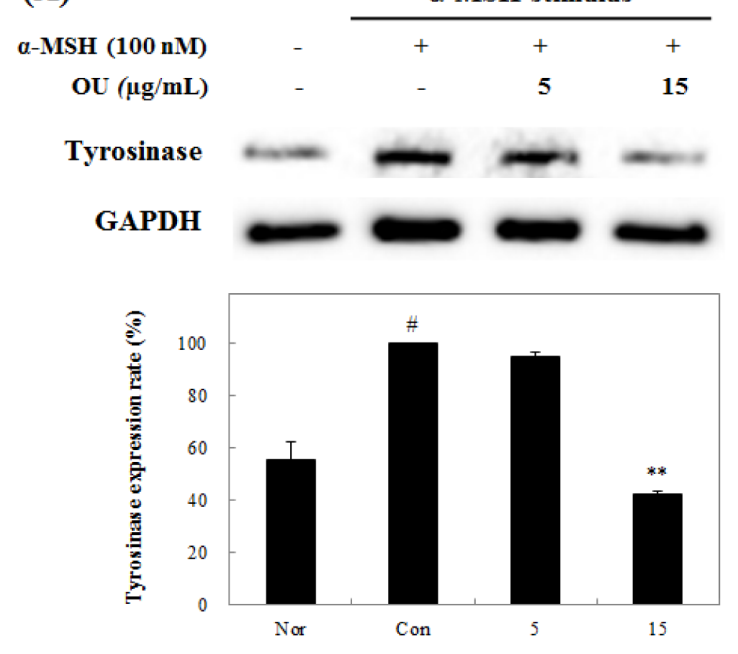

(C)
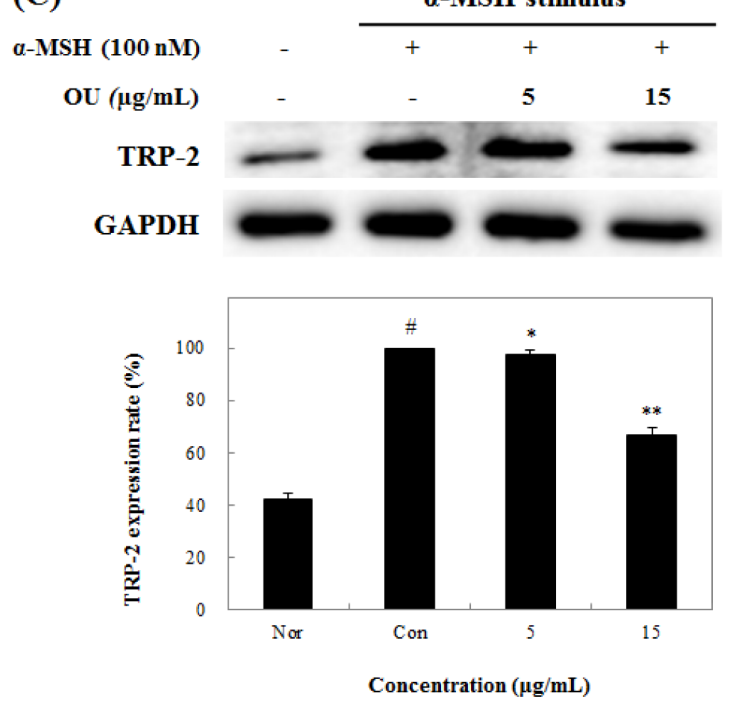

(B)
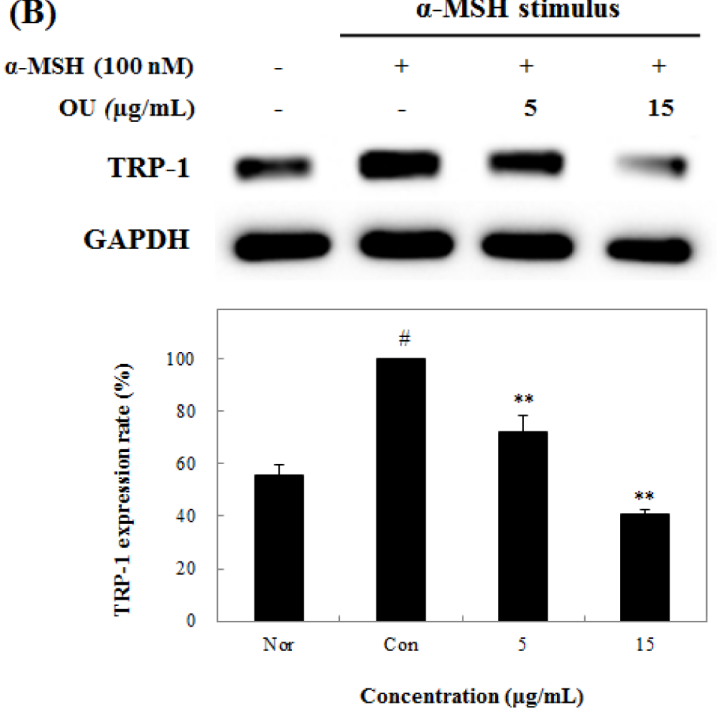

(D)
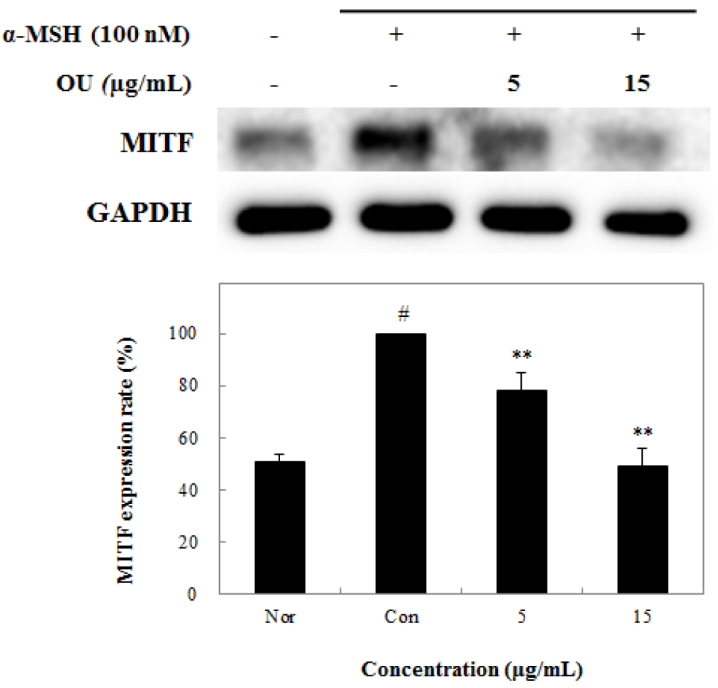

Fig. 4 Protein expression rate of tyrosinase (A), TRP-1 (B), TRP-2 (C), and MITF (D) by phenolics from OU in B16F10 melanoma cells. Lysates were prepared from control or different concentration $(5$ and $10 \mu \mathrm{g} / \mathrm{mL})$ of phenolics. Nor: $\alpha-\mathrm{MSH}$ not induced group, Con: $\alpha$-MSH induced group not treated phenolics. The values are mean $\pm \mathrm{SD}$ of three independent experiments. ${ }^{*} p<0.05$ compared with the Con group, ${ }^{*} p<0.05,{ }^{* *} p<0.01$ compared with the Con group

7. Kinsella JE, Frankel E, German B, Kanner J (1993) Possible mechanism for the protective role of antioxidants in wine and plant foods. Food Technol 47: 85-89

8. Lee YS, Yoon HK, Kim NW (2010) The physiological activities of ripe fruit of Poncirus trifoliata. Kor J Food Preserv 17: 698-705

9. Ju HJ, Lee SA, Kim RH, Park BD, Kim GN (2017) Evaluation of Curcuma longa L. water extracts as beauty food materials in B16F10 and human skin fibroblasts. Asian J Beauty Cosmetol 15: 214-222

10. Urabe K, Aroca P, Tsukamoto K, Mascagna D, Palumbo A, Prota G, Hearing VJ (1994) The inherent cytotoxicity of melanin precursors: a revision. Biochimica et Biophysica Acta 1221: 272-278

11. Lin CB, Babiarz L, Liebel F, Price ER, Kizoulis M, Gendimenico GJ, Seiberg M (2002) Modulation of microphthalmia-associated transcription factor gene expression alters skin pigmentation. Journal of investigative dermatology 119: 1330-1340

12. Lee EH, Kim BO, Cho YJ (2017) Inhibitory activities on biological enzymes of extracts from Oplismenus undulatifolius. J Appl Biol Chem
60(2): 101-108

13. Carmichael J, DeGraff WG, Gazdar AF, Minna JD, Mitchell JB (1987) Evaluation of a tetrazolium based semiautomated colorimetric assay: assessment of chemosen- sitivity testing. Cancer Res 47: 936-942

14. Hosoi J, Abe E, Suda T, Kuroki T (1985) Regulation of melanin synthesis of B16 melanoma cell by 1 alpha, 25-dihydroxyvitamin $\mathrm{D}_{3}$ and retinoic acid. Cancer Res 45: 1474-1478

15. Tsareva SA, Moriggl R, Corvinus FM, Wiederanders B, Schutz A, Kovacic B, Friedrich K (2007) Signal transducer and activator of transcription 3 activation promotes invasive growth of colon carcinomas through matrix metalloproteinase induction. Neoplasia 9: 279-291

16. Kobayashi T, Imokawa G, Bennett DC, Hearing VJ, (1998) Tyrosinase stabilization by Tyrp1 (the brown Locus Protein). J Biol Chem 273: 31801-31805

17. Friedman PS, Wren F, Buffey J, Macnele S (1990) $\alpha$-MSH causes a small rise in cAMP but has no effect on basal or ultra violet-stimulated melanogenesis in human melanocytes. Br J Dermatol 123: 145-151 